\title{
Accuracy of transcutaneous bilirubinometer in assessing jaundice in newborns in Indian context
}

\author{
Sujatha S.G' ${ }^{1}$, Sreenivasan V.K ${ }^{2}$, Aparna Gulvadi ${ }^{3}$, Ramaraj $S^{4}$ \\ ${ }^{1}$ Dr. Sujatha SG, Assistant Professor, ${ }^{2}$ Dr. Sreenivasan V.K. Associate Professor, ${ }^{3}$ Dr. Aparna Gulvadi, Associate \\ Professor, ${ }^{4}$ Dr. Ramaraj S, Professor, all authors are affiliated with Department of Pediatrics, Amala Institute of Medical \\ Sciences (AIMS), Thrissur, Kerala, India.
}

Address for Correspondence: Dr. Sujatha S.G, Assistant Professor, Amala Institute of Medical Sciences (AIMS), Thrissur, Kerala, India. E-mail: drsuja_indy@yahoo.co.in

\begin{abstract}
Background: Jaundice is a very common problem in newborns. Though measuring serum bilirubin is considered the gold standard method for estimating jaundice, Transcutaneous Bilirubin (TCB) measurement by TCB meter is now used in various centers. The accuracy of TCB meter is affected by many factors, skin colour being one of them. Aim: To analyze the accuracy of TCB meter in comparison to serum bilirubin for assessing jaundice in babies with different skin colours, in a tertiary care centre in South India. Methods: The study was performed in 200 babies in a medical college, in South India over a period of five months from august 2016 to December 2016. Term babies upto $7^{\text {th }}$ post natal day without any complications were analyzed. Babies were categorized based on their skin colour into 6 groups using the Fitz Patrick's colour scale. Jaundice was quantified in these babies by TCB meter and by measuring serum bilirubin at the same time and the values were compared. Results: Out of 200 babies, 6 babies were in group 2, 100 in group 3, 83 in group 4 and 11 in group 5. Though the Pearson correlation was linear in all the groups, it was lesser in the dark skinned babies. So we concluded that assessment of jaundice by TCB meter is not accurate in dark skinned babies. Hence serum bilirubin must be done in these babies before intervention. Conclusion: TCB is not accurate in assessing jaundice in dark skinned babies. Still it can be used as a valid screening tool.
\end{abstract}

Keywords: Transcutaneous Bilirubinometer; Fitz Patrick's colour scale; Serum bilirubin; Dark skin

\section{Introduction}

Hyperbilirubinemia is a common neonatal problem. Measurement of total serum bilirubin is often required in the management of jaundiced neonates. Estimation of serum bilirubin is the gold standard method for estimating the jaundice. But it is an invasive procedure requiring blood withdrawal which is painful for the neonate and is also a time consuming procedure.

Transcutaneous bilirubinometry (TCB), being a non invasive method is now being used in many centres to assess jaundice and is considered as a valid screening tool. Cutaneous bilirubin and serum bilirubin have a high correlation and hence Transcutaneous Bilirubinometer (TCB) is used for assessing jaundice in many centers [1-4]. These meters direct light into the

Manuscript received: $4^{\text {th }}$ April 2017

Reviewed: $14^{\text {th }}$ April 2017

Author Corrected: $20^{\text {th }}$ April 2017

Accepted for Publication: 25 ${ }^{\text {th }}$ April 2017 neonate's skin and the intensity of specific wavelength that is returned from the skin is measured. Different transcutaneous bilirubinometers uses different number of wavelengths. The neonate's subcutaneous tissues reflect a spectrum of optical signals which is analyzed by the meter. Photocell in meter converts these optical signals to electrical signal which are then analyzed by a microprocessor to give bilirubin values.

Melanin, dermal maturity, hemoglobin and bilirubin are the major components in the skin of the neonate which can influence the spectral reflectance [5-9].

The aim of this study is to show that TCB values are significantly affected by the melanin content of the skin. Hence is less reliable in dark skinned babies with high melanin content when compared to light skinned babies. 


\section{Materials and Methods}

This study was a prospective observational study conducted in a tertiary care hospital in South India from August 2016 to December 2016 using Drager JM103 TCB meter after obtaining parental consent. Term babies up to 7 th post natal day, delivered in our hospital were included in the study. Preterm babies, post dated babies, babies who received phototherapy, those who underwent exchange transfusion and sick term babies were excluded from the study.

Fitzpatrick scale was used to categorize the babies based on skin colour ranging from I to VI, from light skin colour to the darkest. TCB and serum bilirubin were simultaneously measured in babies who looked clinically jaundiced. TCB values were measured over the sternum. One single device was used and it was taken care that all the measurements were done by a single person throughout the study period. Blood for serum bilirubin was collected simultaneously through venepuncture after strict aseptic precautions and the values were compared. Data obtained was analyzed using SPSS23 software. Pearson correlation coefficient was used to quantify the strength of the relationship between TCB and Total Serum bilirubin.

\section{Results}

A total of 200 babies were included in the study. The gender distribution was equal (50\% boys and 50\% girls). Data's were stratified based on the Fitz Patrick skin colour groups, from group 1 to 6 from fair skin to deeply pigmented dark coloured skin). Of the total 200 babies, 6 babies were in group 2 (3\%), 100 babies in group 3(50\%), 83 babies in group $4(41.5 \%)$ and 11 babies in group 5(5.5\%). Being a tropical country, we didn't have any babies in the group 1 and group 6 categories. Baseline characteristics of the babies are given in Table 1. There was no significant difference in the basic characteristics among the babies in all the groups.

Table-1: Baseline data of neonates in the various groups.

\begin{tabular}{|c|c|c|c|c|c|c|c|c|}
\hline & \multicolumn{2}{|c|}{ Group 2 } & \multicolumn{2}{c|}{ Group 3 } & \multicolumn{2}{c|}{ Group 4 } & \multicolumn{2}{c|}{ Group 5 } \\
\hline & Median & Range & Median & Range & Median & Range & Median & Range \\
\hline Hours of life & 50 & $15-100$ & 56 & $11-140$ & 55 & $13-116$ & 60 & $18-96$ \\
\hline Birth weight(kg) & 3.46 & $2.4-4$ & 3.06 & $2.6-3.8$ & 3 & $2.48-4.4$ & 3 & $3.1-3.7$ \\
\hline TCB & 13.85 & $8.5-16.2$ & 13.85 & $6.5-20.5$ & 14.7 & $7.4-18.5$ & 15.2 & $8-20.3$ \\
\hline Serum Bilirubin & 13.6150 & $\begin{array}{l}9.82- \\
16.11\end{array}$ & 13.62 & $7.4-21$ & 13.43 & $5.76-19$ & 12.67 & $7.80-19.2$ \\
\hline
\end{tabular}

Strength of the relationship between TCB and serum bilirubin was measured by using the Pearson correlation coefficient $\mathrm{r}$ (Table 2). $\mathrm{r}$ was calculated for each category. Group 2 patients $(\mathrm{r}=0.953, \mathrm{p}<0.0001, \mathrm{n}=6)$. In group $3, \mathrm{r}=0.885, \mathrm{p}$ $<0.0001, \mathrm{n}=100$.

In group 4, $\mathrm{r}=0.815, \mathrm{p}<0.0001, \mathrm{n}=83$ and in group $5, \mathrm{r}=0.789, \mathrm{p}<0.0001, \mathrm{n}=11$. Relationship between TCB and serum bilirubin was linear and found to be significant in all the groups, though correlation was lesser in the dark skinned babies ( $\mathrm{r}$ value of 0.953 in group 2 versus 0.789 in group 5 babies).

Table-2: Correlation (Pearson Correlation) between TCB and Serum Bilirubin in various groups.

\begin{tabular}{|c|c|c|c|}
\hline Skin colour Groups & No of cases & Correlation coefficient (r) & p Value \\
\hline 2 & 6 & 0.953 & 0.0001 \\
\hline 3 & 100 & 0.885 & 0.0001 \\
\hline 4 & 83 & 0.815 & 0.0001 \\
\hline 5 & 11 & 0.798 & 0.0001 \\
\hline
\end{tabular}



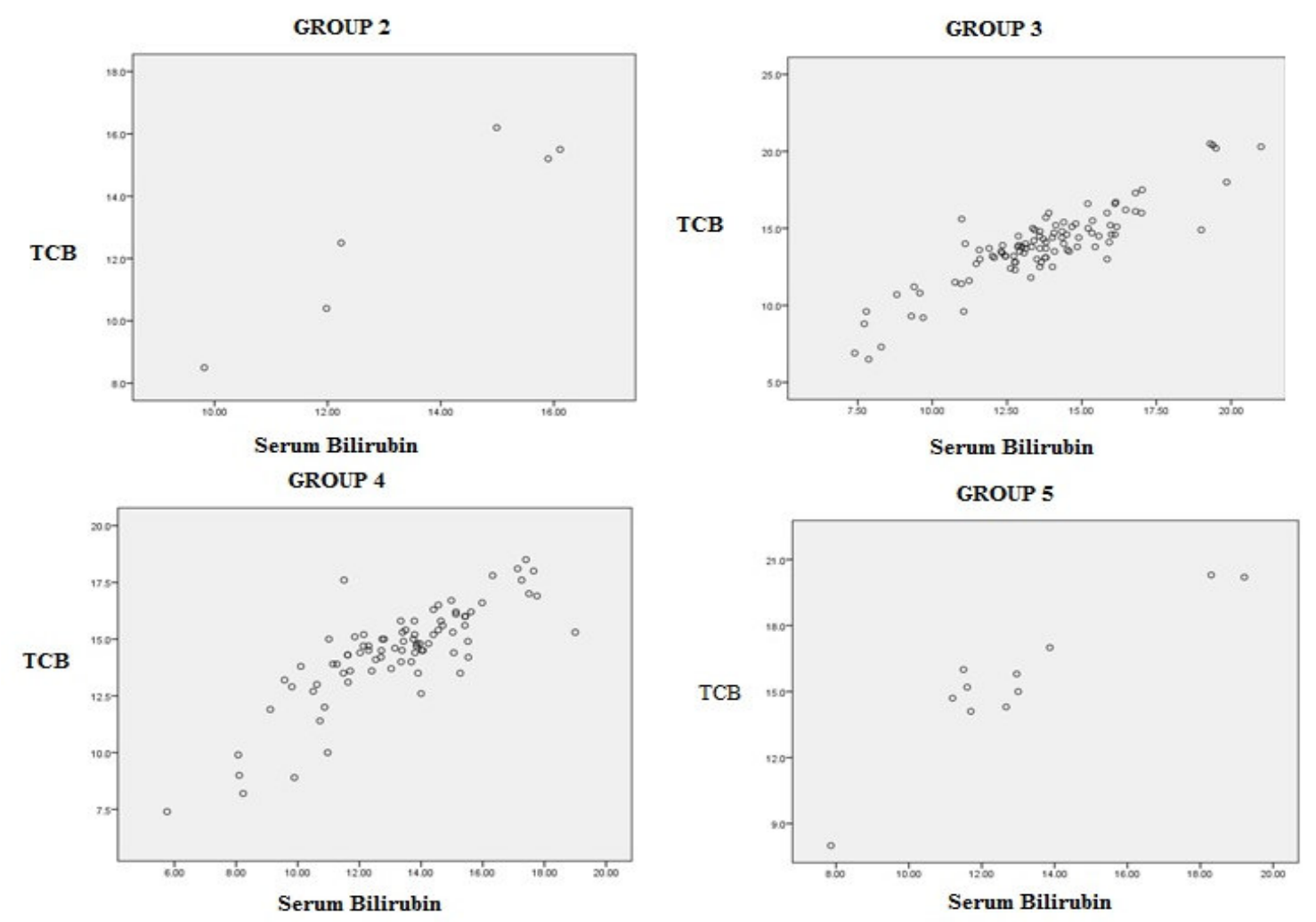

Fig-1: Scattered diagram for each category is given below.

\section{Discussion}

Hyperbilirubinemia is seen commonly in newborns. Assessing the jaundice visually may not be accurate. Accurate measurement of bilirubin is necessary in deciding about the treatment. Gold standard method of assessing jaundice is by estimating serum bilirubin. But unfortunately it is an invasive method and results are not immediate. If serum bilirubin is done in all the babies with clinical jaundice, it will result in unnecessary skin puncture in most of them. Hence many centres are using TCB meters to assess the jaundice levels.

Good correlation is shown between transcutaneously measured bilirubin and serum bilirubin values in full term infants in different studies [1-4]. Some authors concluded that transcutaneous bilirubin (TCB) measurements are not accurate in predicting serum bilirubin and at higher bilirubin values the transcutaneous meters have their limitations [10-12].

Factors like skin thickness, blood flow and content, maturity of the skin and pigmentation may impact the TCB measurement [5-9]. Bhutani et al has reported that TCB is effective in assessing the jaundice in a multi racial population [13]. But in our study we find that skin pigmentation profoundly affects the assessment of jaundice by TCB meter. Another study conducted in Nigerian babies showed that TCB overestimates serum bilirubin by at least $3 \mathrm{mg} / \mathrm{dL}$, which occurs in one out of every three neonates and in some neonates the overestimation was as high as $8 \mathrm{mg} / \mathrm{dL}$.

Another study was done by Afanetti, in both term and preterm babies and in different ethnic backgrounds (Caucasian and non Caucasian), using a second generation TCB meter. 85 measurements of TCB and total serum bilirubin were retrospectively analyzed. Pearson correlation was found to be high in all the groups $(r>0.9)$, though there was a trend for TCB to overestimate total serum bilirubin in non-caucasian babies and in babies $>34$ weeks [14]. In a study conducted by Samiee to study the influence of skin colour on diagnostic accuracy of the jaundice meter in 451 infants, also found a high association between TCB and Total serum bilirubin for all skin colours, though TCB was underestimating TSB in light and medium skin colours and overestimating in dark skin coloured babies [15]. 
In our study, we report the clinical inaccuracy of the TCB meter in assessing the severity of jaundice in dark skinned babies where TCB showed higher values than the serum bilirubin. Our study group comprised of babies with similar demographics for birth weight, gestation and day of life.

The correlation between serum bilirubin and TCB measurement in fair skinned babies (group 2 and 3) was good with $r$ values of 0.953 and 0.885 respectively, which was statistically significant. Whereas the correlation in the dark skinned babies (group 4 and 5) was comparatively less, $r$ values 0.815 and 0.798 respectively. Even though the correlation was good, the actual differences in the values were more in dark skinned babies, making it unacceptable. TCB values were found to be more than serum bilirubin by an average of $3 \mathrm{mg} / \mathrm{dL}$ in group 4 and 5 babies. Many such babies whose TCB was in the phototherapy range were actually in the normal range when a simultaneous serum bilirubin was estimated, thereby avoiding unnecessary admission and interventions in such babies.

Hence we arrived at a conclusion that high TCB values in dark skinned babies is to be confirmed by serum bilirubin values before initiating treatment. This will avoid unnecessary admission and treatment of such babies.

The limitation in our study was that the sample size was not uniform among all the groups. And being a tropical country, we did not have babies in group 1 and 6 . Also extreme high values of bilirubin were not analyzed in our study. Other confounding factors like blood flow and hemoglobin was not taken into account.

\section{Conclusion}

TCB is not accurate in assessing jaundice in dark skinned babies. Still it can be used as a screening tool.

\section{Abbreviations: TCB-Transcutaneous Bilirubin \\ Funding: Nil, Conflict of interest: None initiated, Perission from IRB: Yes}

\section{References}

1. Grohmann K, Roser M, Rolinski B, Kadow I, Müller C, Goerlach-Graw A, Nauck M, Küster H. Bilirubin Measurement for Neonates: Comparison of 9 Frequently Used Methods. Pediatrics. 2006; Apr; 117 (4) : 1174-1183.
2. Maisels MJ, Ostrea EM Jr, Touch S, Clune SE, Cepeda E, Kring E, Gracey K, Jackson C, Talbot D, Huang R. Evaluation of a new transcutaneous bilirubinometer. Pediatrics. 2004 Jun;113(6):1628-35.

3. Tan KL, Chia HP, Koh BC. Transcutaneous bilirubinometry in Chinese, Malay and Indian infants. Acta Paediatr.1996 Aug;85(8):986-90.

4. Maisels MJ, Kring E. Transcutaneous bilirubinometry decreases the need for serum bilirubin measurements and saves money. Pediatrics. 1997 Apr; 99 (4):599-601.doi: 10.1542/peds.99.4.599.

5. Knudsen A, Ebbesen R. Transcutaneous bilirubinometry in neonatal intensive care units. Arch Dis Child Fetal Neonatal Ed. 1996 Jul;75(1):F53-56. doi: 10.1136/fn.75.1.F53.

6. Grande R, Gutierrez E, Latorre E, Arguelles F. Physiological variations in the pigmentation of newborn infants. Hum Biol. 1994 Jun;66(3):495-507.

7. Onks D, Silverman L, Robertson A. Effect of melanin, oxyhemoglobin and bilirubin on transcutaneous bilirubinometry. Acta Paediatr. 1993 Jan; 82 (1):19-21.

8. Wang L, Jacques SL, Zheng L. MCML--Monte Carlo modeling of light transport in multi-layered tissues. Comput Methods Programs Biomed. 1995 Jul;47 (2): $131-46$

9. Jacques SL. Path integral description of light transport in tissue. Ann N Y Acad Sci. 1998 Feb 9; $838: 1-13$.

10. Szabo $\mathrm{P}$, Wolf $\mathrm{M}$, Bucher HU, Fauchère JC, Haensse D, Arlettaz R. Detection of hyperbilirubinaemia in jaundiced full-term neonates by eye or by bilirubinometer? Eur J Pediatr. 2004 Dec; 163(12):722-7.

11. Dai J, Parry DM, Krahn J. Transcutaneous bilirubinometry: its role in the assessment of neonatal jaundice. Clin Biochem. 1997 Feb;30(1):1-9.

12. Beck M, Kau N, Schlebusch H. Transcutaneous bilirubin measurement in newborn infants: evaluation of a new spectrophotometric method. Arch Dis Child Fetal Neonatal Ed. 2003 Jul; 88(4):F350-351. doi: 10.1136/ fn. 88.4.F350-b. 
13. Bhutani VK, Gourley GR, Adler S, Kreamer B, Dalin C, Johnson LH. Noninvasive measurement of total serum bilirubin in a multiracial predischarge newborn population to assess the risk of severe hyperbilirubinemia. Pediatrics. 2000 Aug;106(2):E17.

14. Afanetti M, Eleni Dit Trolli S, Yousef N, Jrad I, Mokhtari M. Transcutaneous bilirubinometry is not influenced by term or skin color in neonates. Early Hum
Dev. 2014 Aug; 90 (8):417-20. doi: 10.1016/j. earlhumdev. 2014. 05.009. Epub 2014 Jun 11.

15. Samiee-Zafarghandy S, Feberova J, Williams K, Yasseen AS, Perkins SL, Lemyre B. Influence of skin colour on diagnostic accuracy of the jaundice meter JM 103 in newborns. Arch Dis Child Fetal Neonatal Ed. 2014 Nov; 99 (6):F480-4. doi: 10.1136/archdischild2013-305699. Epub 2014 Jul 29.

\section{How to cite this article?}

Sujatha S.G, Sreenivasan V.K, Aparna Gulvadi, Ramaraj S. Accuracy of transcutaneous bilirubinometer in assessing jaundice in newborns in Indian context. J PediatrRes.2017;4(04):268-272.doi:10.17511/ijpr.2017.i04.05. 